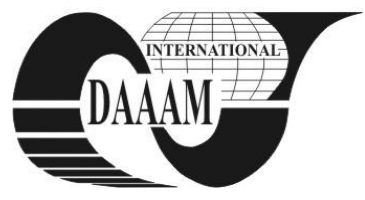

\title{
APPLICATION OF FINRAY EFFECT APPROACH FOR PRODUCTION PROCESS AUTOMATION
}

\author{
PFAFF, O[ndrej]; SIMEONOV, S[imeon]; CIROVIC, I[van] \& STANO, P[avol]
}

\begin{abstract}
This paper focuses the topic FinRay Effect ${ }^{\circledR}$ use in practice. For explain the concept FinRay Effect ${ }^{\circledR}$ is a done brief search of problems. There are many devices using FinRay Effect ${ }^{\circledR}$, but this paper is limited to manipulators and grippers. Further there is done a review of manipulators developed by Festo $A G$ \& Co. KG.

Key words: FinRay effect ${ }^{\circledR}$, bionic tripod, manipulator
\end{abstract}

\section{INTRODUCTION}

Many new technical solutions created by bionic (natural) patterns. Nature shows the new technical approaches for designing and solving technical tasks effectively. The target of bionic solutions is to get, high-tech equipment operating on high performance with low consumption of energy supplied. Many bionic solutions usually have very good parameters based on simple processes. Often these processes are very difficult to describe mathematically and therefore, their technical imitation and control is difficult.

\section{FINRAY EFFECT®}

In 1997, Leif Kniese was on fishing holiday in Norway, where he happened to make an important discovery. If you push your finger to the side of the fish fins, it doesn't bend in the direction of force, but in the opposite direction (against the applied force). He watched it on the first caught fish, and then he verified this discovery on other fish and in all cases there was the same result. After returning from Norway to Germany he continued in discovering of this principle. He continued in exploration of anatomy of fish fins with Rudolf Bannasch in the laboratory of Berlin company EvoLogics $\mathrm{GmbH}$. After some time, they accurately defined the principles with which the fish move and they called it FinRay Effect ${ }^{\circledR}$. This principle is already patented by the company EvoLogics $\mathrm{GmbH}$.

The structure is surprisingly simple. Fish have a basic structure consisting of two bones that are attached by elastic connective tissue. The tail fin is the prime mover for movement. It consists of several basic structures stacked one above the other. It is very important that the structure is light but strong enough, because excess weight is inappropriate in terms of energy losses. The design simulating a fish fin consists of two longitudinal fibers, which are on either side (top) attached. Among the longitudinal fibers are cross fibers that keep the whole structure after assembly. The longitudinal and cross fibers are connected with flexible links that allow movement between them.

The Fig. 1. shows the basic structure in the unloaded state. The Fig. 2. illustrates the basic structure of the loaded side force from a finger. The structure is deformed and responds to the burdensome force and tries to hug your finger. The top structure is turned against the direction of the applied force.

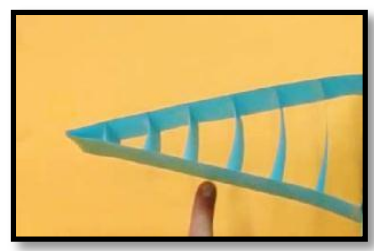

Fig. 1. Unloaded structure

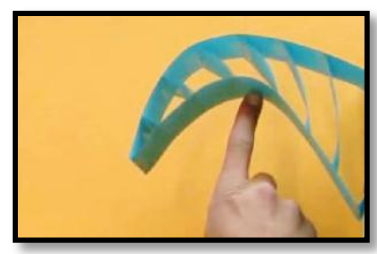

Fig. 2. Load structure

\section{TWO WAYS USE STRUKTURE WITH FINRAY EFFECT®}

There are two ways to use structures with FinRay Effect ${ }^{\circledR}$. One way is to use is when the structure forms a manipulator (Fig. 3 ). The second way is when the structure forms a finger gripper, which adaptively adjusts the shapes of objects transmitted (Fig. 4). To create a gripper there should be at least two fingers which act against each other and thereby maintain the carrying of the objects.

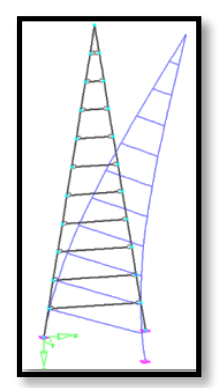

Fig. 4. The structure forms a finger gripper$$
\text { Fig. 3. The }
$$

To move the structure forms manipulator end point is a manipulator necessary to change the relative position of the beginning of the longitudinal fibers. In Fig. 3 . it is a structure with only two longitudinal fibers, the manipulator only allows twodimensional motion (2D). To achieve three-dimensional motion (3D) must be structure supplemented by other longitudinal fibers, which lie in the plane perpendicular to the plane of the two original fibers. The structure need not consist of only two or three longitudinal fibers, it can be consist of more than three fibers as described in chapter 4 .

\section{EXAMPLES OF APPLICATION FINRAY EFFECT® IN PRACTICE OF COMPANY FESTO AG \& CO.. KG}

\subsection{The bionic tripod 1.0}

BionicTripod shows the ability of adopting a bionic design principle for the effective use of automation. The main benefits of the Bionic Tripod include: flexibility, low weight to weight ratio of the transmitted, energy-efficient, controllable structure, dynamic dimensional movement, large range of operations.

BionicTripod consists of three fiberglass rods organized in pyramid shape. The interface between BionicTripod the and transmitted part is done by adaptive FinGripper, which is based on FinRay Effect ${ }^{\circledR}$. 


\subsection{The bionic tripod 2.0}

The horizontal tripod is rotated by 90 degrees from normal configuration and can move by up to 90 degrees within a large workspace. The resulting elasticity and flexibility is ideal for tasks involving man-machine interaction, such as sorting of fruit and vegetable in farming, sorting materials for recycling in industry, or as a "third hand". Integrated and adaptive FinGripper with ball joint with three degrees of freedom and a 30-degree bend range, based on the function of the human wrist, the tripod gives maximum flexibility for grip and deposition of objects in different positions and heights.

\subsection{The bionic tripod 3.0}

Bionic Tripod 3.0 has a new concept of imposing a tripod. The tripod is located vertically above the working table. Tripod consists of four rods made of spring steel organized in pyramid shape. This design achieves a large workspace. Tripod can be bent by $90^{\circ}$ from the vertical axis on each side. The gripper working on FinRay Effect $\AA$ is placed at the end of the tripod to snap objects.

This variant of the tripod is suitable for handling objects, sorting and assembly. It is suitable for a wide variety of tasks in three-dimensional space, especially with small objects. It is deal anywhere where there is a need for transfering small objects quickly and flexibly. In such cases, it uses light and flexible structure which is also solid and stable. Maximum transferred weight is $400 \mathrm{~g}$.

\section{ADVANTAGE AND DISADVANTAGE BIONIC TRIPOD}

One of the main advantages is the safety of the manipulator in collision. The manipulator is only bended or twisted when it crashes with another robot or on a solid obstacle. After it leaves the collision position, the manipulator returns to the original position without permanent deformation, and it can continue working. This can be used to insert components to holes, fixtures, boxes, sleeves, etc.

Another advantage is the very low weight of moving parts which leads to a reduction in inertial forces. It is an advantage at dimensioning drives. Simple construction and adjustable structure of the manipulator are other benefits. Due to the simple design are: simple production, a few parts, simple part, quick and easy installation, easy adjustment of the structure. This has a positive effect on the price.

The disadvantages include a relatively low load manipulator, but the ratio of the weight transmitted to the weight of the arm is high. Location of at manipulator end point is influenced by the weight of the transferred subject. This should be taken into considered when positioning control arm in the control software, which is also for this reason rather complicated.

\section{PROBLEMS}

The main problems which have the Bionic Tripod are due to from disadvantages which were discussed in the previous chapter.

\section{OUR MODEL}

For better imagination of problems FinRay Effect ${ }^{\circledR}$ and identifying the applicability of handling ability was designed and then produced a working model of the manipulator with FinRay Effect ${ }^{\circledR}$ (Fig. 5). The design of our manipulator consists of production simple parts. The structural design was influenced by many conditions: easy and cheap production, demountable, using available materials. Measuring of the position of the manipulator end point was done on the produced model. The obtained values were statistically modified and regression functions are created. A supposed workspace (Fig. 6) was drawn according to regression function. The end points of curves and all curves are measured accurately. A supposed workspace is drawn in the $\mathrm{XY}$ plane. Logically it could by thought that after a rotation around the $\mathrm{z}$ axis we get the whole workspace, but it is not like that. When we created regression functions it

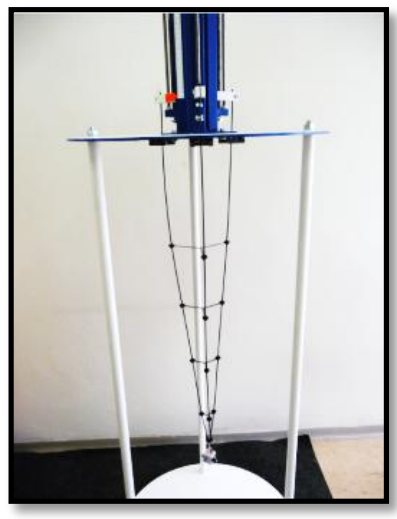

Fig. 5. Our model of manipulator proved that the working space will be asymmetric, which is more difficult to create a workspace

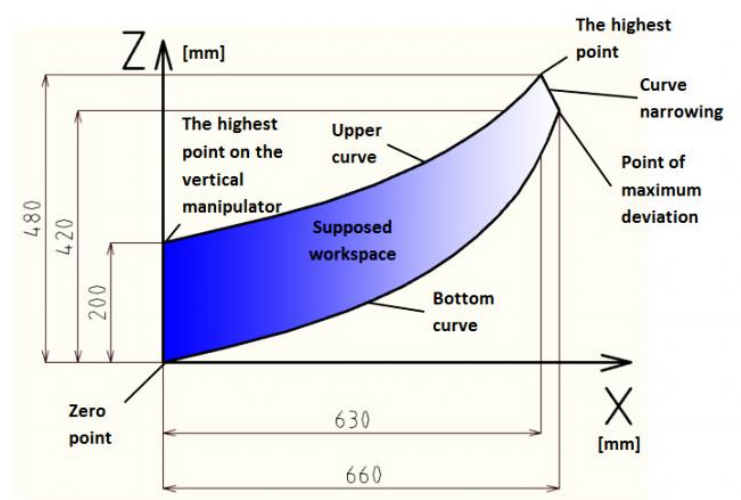

Fig. 6. Supposed workspace

\section{FURTHER WORK}

This topic provides many tasks, which aren't solved, and many questions that need to find answers. The target of further work is creation of manipulator working with FinRay Effect $\AA$, which can be used in an automatic manufacturing process as a full industrial robot.

\section{CONCLUSION}

Manipulators with FinRay Effect ${ }^{\circledR}$ have their advantages and disadvantages. These manipulators will probably not be replaced in all applications where we are now using manipulators with a serial or parallel kinematics. But definitely there will be applications where their benefits will apply and will excel. The result of this research is to verify if these manipulators use in practice or their use limited.

\section{REFERENCES}

***PFAFF, Ondřej. Aplikace Fin Ray principu pro automatizaci výrobních procesů. Brno, 2010. 53 s. Master's thesis. VUT Brno

***http://www.suite101.de/content/fin-ray-effectflossenstrahleffekt-a49022 Accessed: 2011-06-02

***http://www.bionischeinnovationen.de/download/Projektblatt_finrayeffect.pdf Accessed: 2011-05-14

***http://www.bionik-vitrine.de/fin-ray-effect.html Accessed: 2011-06-13

***http://www.festo.com/bionic Accessed: 2011-06-11

This paper was financially supported by specific project FSI-S-11-5. 